\title{
Characterization and Anti-aging Tests of Peel-Off Gel Masks Made from Ethanolic Extract of Yarrow (Achillea millefolium)
}

\author{
Syamsuri Syakri*iD, Isriany Ismail(D), Nurul Muamanah Amal(D), Nur Asma Masjidi(D, Karlina Amir Tahir(iD) \\ Department of Pharmacy, Faculty of Medicine and Health Sciences, UIN Alauddin Makassar, Sulawesi Selatan, Indonesia
}

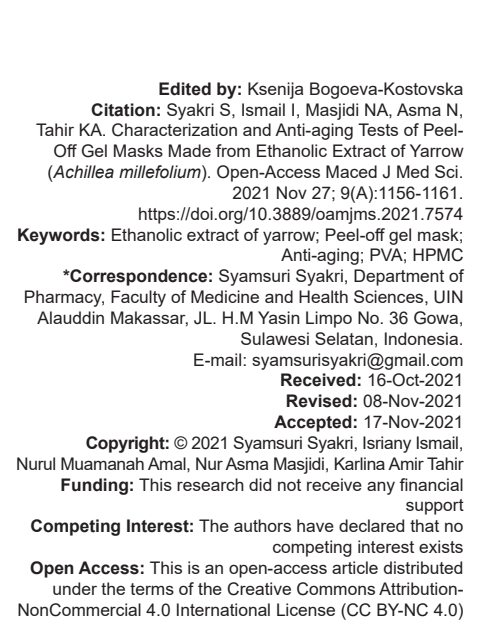

\begin{abstract}
BACKGROUND: Yarrow extract (Achillea millefolium) is recognized to have powerful antioxidants that protect the skin from free radical damage, skin whitening, and anti-aging properties. As a result, the application of antioxidants on the skin can be packaged into a peel-off gel mask preparation for face skin care.

AIM: Therefore, the goal of this study is to see how different concentrations of the polyvinyl alcohol (PVA) and hydroxypropyl methyl cellulose (HPMC).

METHODS: To obtain five formulas that will be made uses preparations and evaluate the quality of the preparations, this research method used quantitative analysis methods and statistical analysis using one-way ANOVA by varying the concentrations of PVA $(7-10 \%)$ and HPMC $(2-4 \%)$ to obtain five formulas that will be made into preparations and evaluated the quality of the preparations. Organoleptic, homogeneity, $\mathrm{pH}$, syneresis, skin irritation, viscosity, spreadability, and drying time of the mask were all evaluated.

RESULTS: The results of the experiment with different concentrations of the PVA and HPMC enhanced dispersion and drying time $(p<0.05)$, but had no effect on decrease viscosity value.

CONCLUSION: The quality of the peel-off gel mask prepared from the ethanolic extract of yarrow was significantly affected by PVA and HPMC concentrations.
\end{abstract}

\section{Introduction}

The compound of Yarrow is essential oil with a range of concentration of $0.21 .0 \%$, with the highest concentration of chamazulene $(640 \%)$, camphor $(20 \%)$, pinene (23\%), and 18 cineol (up to $10 \%$ ). Flavonoids, coumarins, and tannins are also present in the oil [1].

Flavonoids (apigenin, rutin, luteolin, and kaempferol) and essential oils are the principal active constituents in yarrow [2].

The yarrow extract (Achillea millefolium) is a useful cosmetic component for skin rejuvenation. The findings of an in vivo test to examine the possible antiinflammatory effect of a 2-month therapy with a cosmetic formula comprising a concentration of $2 \%$ yarrow extract (A. millefolium) on the appearance of wrinkles and wrinkled pores, as well as skin suppleness [3]. Cosmetic product formulations having $0.1-0.5 \%$ ingredients that really contain a $2 \%$ concentration of yarrow extract (A. millefolium) did not induce skin irritation in clinical studies [4].

Skin is the outermost covering of an animal's or human's body that protects them from the environment. Certain changes in the skin occur as people age, and these changes are impacted by both external and internal factors. Wrinkles, sagging skin, age spots, and dryness, as well as fat loss that causes the skin to lose its natural smoothness, are some of the most evident indications of aging in the skin [5]. The epidermis thins with age, despite the fact that the number of cell layers remains constant. The skin's ability to repair itself steadily deteriorates, and our bodies create less collagen and elastin, causing it to lose its suppleness. Furthermore, when the number of melanocytes declines, the aging skin thins, becomes whiter, and clearer, and develops huge pigment spots and age spots. All of these symptoms necessitate antiaging treatment with anti-aging products or therapies to boost collagen production or slow down natural collagen loss. Although Vitamin D synthesis requires exposure to the sun, damaging UV rays induce premature aging, the development of reactive oxygen species, skin cancer, and the breakdown of extracellular matrix components [6].

Although Vitamin $D$ synthesis requires exposure to the sun, damaging UV rays induce premature aging, the development of reactive oxygen species, skin cancer, and the breakdown of extracellular matrix components [6], [7]. Prolonged exposure to UV radiation of human skin may cause several damages. These damages include skin cancer, sunburn, oxidative stress, and photoaging [8]. The aging process is an inevitable physiological process that 
will be experienced by every human being. This process is irreversible which covers all organs of the body including the skin [10], but anti aging definition is not always meaning the biological process that changes in organism; it has been changed and emphasizes more on the quality of life [11], [12], [13], [14], [15], [16], [17], [18], [19].

Photoprotection and subsequent treatment with exogenous antioxidants and other chemicals that our systems cannot generate are the main strategies for preventing premature aging. Polyphenol compounds are one of the most efficient anti-aging substances because they limit oxidative skin damage by decreasing the generation of reactive oxygen species triggered by external (UV radiation) and endogenous factors [7]. As a result, antioxidants are commonly used in skin care products, particularly anti-aging treatments, to protect the skin from the impacts of free radicals [9]. The leaves of yarrow $A$. millefolium, which are known to have powerful antioxidants, skin whitening, and skin regeneration [11], contain natural antioxidants. A gel is a dispersion system with at least two phases, such as a solid phase and a liquid phase (li foil gel) or a solid phase and a gas-forming phase (xerophilic gel) [12] Thixotropic, good spread ability, non-greasy, simple to remove, emollient, stain remover, non-staining, and proportional to the amount of excipients are the recommended qualities of dermatological gels [13]. Gels are made by mixing an organic, inorganic, or aqueous solvent or solvents with a gelling agent, which can be a natural, synthetic, or semi-synthetic polymer or a lowmolecular-weight small molecule. The polymer in the gel serves as the gel matrix's backbone [14]. Examples of polymers are carbomer, NaCMC, polyvinyl alcohol (PVA), and others [15].

A face mask, which is formed into the creation of natural facial masks that are effective for eliminating wrinkles on the face, is one of the herbal cosmetic items on the market. Cosmetics made from natural components are seen to be more ecologically friendly, better, and safer, therefore for facial skin care, gel masks made from natural materials, particularly peel-off facial masks, are popular because they may revitalize the skin [9]. When this mask dries, the skin will experience changes that feel like it is pulling the skin layer and providing skin refreshment. It can absorb excess oil, lift debris from the skin's surface, and help clear clogged pores or lure blackheads to the surface [16]. Gels can be used to make a variety of topical therapies, such as facial masks. However, different types and quantities of gelling agents are required for different active components to generate high-quality formulations.

Therefore, the formulation and assessment of peel-off gel mask preparations made from the ethanolic extract of yarrow ( $A$. millefolium) as anti-aging will be carried out based on some of the aforementioned descriptions.

\section{Methods}

\section{Sample preparation}

\section{Easy to make}

Yarrow (A. millefolium) weighing up to $2 \mathrm{~kg}$ was collected and sorted wet. Then, using running water, clean it. Then comes the chopping, which is followed by drying in a drying cabinet.

\section{Production of simplicia powder}

The dried simplicia was place in a blender and blend until smooth. After blending until smooth, weigh $500 \mathrm{~g}$ of yarrow powder. Then, it was placed in a jar.

\section{Production of extracts}

The maceration process was used to extract a yarrow (A. millefolium) from $3.5 \mathrm{~L}$ of $70 \%$ ethanol solvent which was used to extract up to $500 \mathrm{~g}$ of yarrow powder. For $324 \mathrm{~h}$, stirring was done every $128 \mathrm{~h}$. Then, it was filtered. The solvent was then evaporated using a vacuum rotary evaporator set to $70^{\circ} \mathrm{C}$ until a thick extract was produced.

\section{Formulation of the preparation}

\section{Formula design}

Table 1 shows the design of the ethanolic extract of yarrow (A. millefolium) peel-off gel mask preparation formula.

Table 1: Formula for preparing a peel-off gel mask with ethanolic extract of yarrow (Achillea millefolium)

\begin{tabular}{lllllll}
\hline Ingredient & Utility & \multicolumn{7}{l}{ Concentration (\% b/b) } \\
\cline { 3 - 7 } & & F.I & F.II & F.III & F.IV & F.V \\
\hline Yarrow extract & Active substance & 2 & 2 & 2 & 2 & 2 \\
Polyvinyl alcohol & Film forming & 7 & 7.75 & 8,5 & 9.25 & 10 \\
Hydroxypropyl & Gelling agent & 4 & 3.5 & 3 & 2.5 & 2 \\
methyl cellulose & & & & & & \\
Methylparaben & Preservative & 0.18 & 0.18 & 0.18 & 0.18 & 0.18 \\
Glycerin & Humectan & 5 & 5 & 5 & 5 & 5 \\
Aquadest & Solvent & ad 100 & ad 100 & ad 100 & ad 100 & ad 100 \\
\hline
\end{tabular}

Making a gel mask that peels off (Do not start a sentence with an abbreviation)

PVA was dissolved in $20 \mathrm{ml}$ distilled water at $80^{\circ} \mathrm{C}$, then melted on a bath while stirring until homogenous and clear (solution A). Hydroxypropyl methyl cellulose (HPMC) was first created by dissolving $20 \mathrm{ml}$ aquadest in a mortar at $80^{\circ} \mathrm{C}$ and crushing it (solution $\mathrm{B}$ ). In the mortar, solution $A$ and solution $B$ combine while stirring until smooth. Then, using glycerin to dissolve the methyl paraben, it was homogenized. The yarrow ethanol extract was dissolved in aquadest, then slowly added to the base, homogenized, and finally removed. The leftover aquadest was then taken care of. The remaining aquadest was then 
added to $100 \mathrm{~g}$ of water and homogenized. After that, it's sealed in a container [17].

\section{Evaluation}

\section{Organoleptic evaluation}

The physical form of the peel-off gel mask preparation of the ethanol extract of yarrow (A. millefolium) was observed directly, including smell, color, and texture [18].

\section{Homogeneity test}

This test is carried out by smearing the sample on a glass item and inspecting the particles contained in the preparation [18].

\section{Acid-base balance}

This test is performed by dipping the $\mathrm{pH}$ meter into the mask preparation and recording the $\mathrm{pH}$ [20].

\section{Viscosity measurement}

This test was performed by dipping the spindle into the gel mask preparation and then performing the test. The viscosity was then measured using a Brookfield viscometer at a speed of $10 \mathrm{rpm}$ using spindle number 64 [21]

\section{Test for spreadability}

This test was carried out by carefully placing a $0.5 \mathrm{~g}$ gel mask preparation on a glass measuring $20 \times 20 \mathrm{~cm}$. Then add a $125 \mathrm{~g}$ weight and top with another glass. After that, after $1 \mathrm{~min}$, the diameter was measured [21].

\section{Syneresis examination}

This test was carried out by storing the gel at $10^{\circ} \mathrm{C}$ for 24,48 , and $72 \mathrm{~h}$. Each of these gels is placed in a package to keep the water that is released during storage contained. The weight loss during storage was measured and compared to the initial weight of the gel to determine syneresis [22].

\section{Test for skin irritation}

This test is perform by placing a gel mask preparation with a diameter of $3 \mathrm{~cm}$ behind the ear, leaving it on for 20-30 min, then removing it and observing changes in the form of itching, redness, and swelling of the skin [23].

\section{Time to dry the mask}

This test is perform by putting $1 \mathrm{~g}$ of mask preparation to the back of the hand's skin and measuring the dry speed to build a peeling layer from the gel phase with a timer [18].

\section{Examination of data}

The data from evaluation of the preparations mentioned above were analyzed using standard requirements parameters and viscosity tests, spreadability tests, and mask drying time tests. Statistical analysis of related parametric or nonparametric tests [24].

\section{Results}

\section{Extraction result}

Table 2: Yarrow extraction results (Achillea millefolium)

\begin{tabular}{llll}
\hline Extract type & Simple weight & Extract weight & $\%$ yield \\
\hline Thick extract & $500 \mathrm{~g}$ & $19.17 \mathrm{~g}$ & 3.834 \\
\hline
\end{tabular}

\section{Organoleptic test result}

Table 3: Organoleptic test results for peel-off gel mask made from ethanol extract of yarrow (Achillea millefolium)

\begin{tabular}{llll}
\hline Masks formula & Test parameters & & \\
\cline { 2 - 4 } & Color & Smell & Texture \\
\hline II & Brownish-green & Extract fragrance & Semi-solid \\
III & Brownish-green & Extract fragrance & Semi-solid \\
IIV & Brownish-green & Extract fragrance & Semi-solid \\
V & Brownish-green & Extract fragrance & Semi-solid \\
\hline
\end{tabular}

\section{Test results on homogeneity and $\mathrm{pH}$}

Table 4: Results of homogeneity, $\mathrm{pH}$, and skin irritation tests for a peel-off gel mask made from yarrow ethanol extract (Achillea millefolium)

\begin{tabular}{llll}
\hline Masks formula & Test parameters & & \\
\cline { 2 - 4 } & Homogeneity & $\mathrm{pH}$ & Inflammation of the skin \\
\hline I & Homogeneous & 6.07 & No irritation \\
II & Homogeneous & 6.09 & No irritation \\
III & Homogeneous & 6.11 & No irritation \\
IV & Homogeneous & 6.16 & No irritation \\
V & Homogeneous & 6.23 & No irritation \\
\hline
\end{tabular}

\section{Syneresis and skin irritation test result}

Table 5: Syneresis and skin irritation test result for peel-off gel mask preparations made from ethanolic extract of yarrow (Achillea millefolium)

\begin{tabular}{llllll}
\hline Time (hour) & \multicolumn{2}{l}{ Masks formula } & & \\
\cline { 2 - 6 } & F.I & F.II & F.III & F.IV & F.V \\
\hline 24 & $0.58 \%$ & $0.49 \%$ & $0.47 \%$ & $0.38 \%$ & $0.29 \%$ \\
48 & $0.78 \%$ & $0.69 \%$ & $0.57 \%$ & $0.48 \%$ & $0.38 \%$ \\
72 & $1.19 \%$ & $0.99 \%$ & $0.76 \%$ & $0.57 \%$ & $0.48 \%$ \\
\hline
\end{tabular}




\section{Mask viscosity, spreadability, and drying time test results}

Table 6: Viscosity, dispersion, and drying time of a peel-off gel mask made from yarrow ethanol extract (Achillea millefolium)

\begin{tabular}{llll}
\hline Masks formula & Viscosity value $(\mathrm{cP})$ & $\begin{array}{l}\text { Spreadability } \\
(\mathrm{cm})\end{array}$ & $\begin{array}{l}\text { Drying time } \\
\text { (minutes) }\end{array}$ \\
\hline I & & 5.4 & 31 \\
II & 37,700 & 5.3 & 29 \\
III & 37,920 & 5.1 & 28 \\
IV & 38,420 & 5.0 & 27 \\
V & 40,700 & 4.8 & 30 \\
\hline
\end{tabular}

\section{Discussion}

The yarrow plant $(A$. millefolium) has a wide range of medical applications and is extremely valuable as a herbal medicine, with various components of the plant, particularly the leaves, being effective in preventing nosebleeds and wound healing [25]. Not only that, but also this yarrow can also revitalize the skin because it contains powerful antioxidant chemicals that protect the skin from free radical damage.

According to prior study, $2 \%$ yarrow extract does not cause irritation in most people. It can also reduce the appearance of wrinkles and wrinkled pores, as well as increase skin softness [3]. The leaf extract was formed into a peel-off gel mask preparation using range $7-10 \%$ concentration of PVA as a film-forming agent [26], and $2-4 \%$ concentration of hydroxypropyl methylcellulose as a gelling agent in this work [26]. As a result, it was made into a peel-off gel mask preparation with the goal of determining the influence of PVA and HPMC concentrations on the quality of the yarrow extract mask preparation as an anti-aging agent.

The ingredients found in yarrow ( $A$. millefolium) are known to have strong antioxidant activity, brightening skin, and skin rejuvenation [11]. The extraction process in this study used $70 \%$ ethanol solvent with maceration method, which aims to attract phenolic compounds that are efficacious as antioxidants [27]. After maceration, the thick extract weighing $19.17 \mathrm{~g}$ was evaporated.

All peel-off gel mask formulations had a dark green hue, a characteristic extract fragrance, and a semi-solid texture, according to the results of the organoleptic tests. The brownish-green hue and distinct fragrance of the extract on this peel-off gel mask are the result of the use of $2 \%$ yarrow ethanolic extract to affect color and odor alterations.

When applied to a glass object, the homogeneity test revealed that all peel-off gel mask preparations did not display any coarse granules. The gel arrangement was deemed to be homogeneous if no coarse particles were identified and the color equation was complete [28]. In this situation, the finished product is homogeneous in composition.
All peel-off gel mask compositions passed the $\mathrm{pH}$ test and were in the skin $\mathrm{pH}$ range of 6 . The physiological $\mathrm{pH}$ of the skin was 4.5-6.5, according to the Cosmetics book [29]. In this scenario, the more alkaline or the more acidic the substance, the more damage it can bring to the skin, including dry, cracked, sensitive, and easily infected skin.

There were no alterations in the form of redness, itching, or swelling of the skin in the skin irritation test utilizing five probands with diverse skin types, including normal, oily, dry, combination, and sensitive skin.

The syneresis test is use to see if there is any liquid on the surface of the gel. Because the drop in weight of the preparation was $<2 \%$, the percentage findings obtained in Table 5 did not experience syneresis. As a result, the preparation was declared stable because it lacked a layer of water on the surface and had no effect on the gel preparation's stability [30].

The viscosity of a liquid is a measure of its resistance to flow; the higher the viscosity, the greater the resistance [31]. The significance value for the concentrations of PVA and HPMC had a significant effect on the viscosity of the peel-off gel mask of the ethanol extract of yarrow (A. millefolium) as anti-aging, according to the results of statistical analysis using the one-way ANOVA test. A good viscosity value, according to $\mathrm{SNI}$ 16-4380-1996, is between 3000 and 50,000 cP. The viscosity of the five preparations increased in the range of $37,700-43,820 \mathrm{cP}$, according to the data (Table 6). As a result, the five preparations are sufficient. The viscosity of the peel- off gel mask preparation can be increased by increasing the concentration of PVA and HPMC [32].

The dispersion test is used to determine how well the gel preparation spreads on the skin surface, as this can affect drug absorption and the rate at which active substances are released at the application site [33]. Agood gel will spread more slowly and have a high dispersion value [32]. The significance value for the concentration of PVA and HPMC had a significant effect on the dispersion of the peel-off gel mask of the ethanol extract of yarrow (A. millefolium) as anti-aging, according to the results of statistical analysis using the one-way ANOVA test. For gel preparations, a good dispersion of 5-7 cm is required [34]. The dispersion findings in formulas I-IV are in the range of $5.0-5.4 \mathrm{~cm}$, indicate that they have good dispersion, whereas formula $V$, at $4.8 \mathrm{~cm}$, indicates that it does not have good dispersion. The easier the gel preparation is rubbed, the greater its capacity to spread [35].

This mask preparation was used in the drying time test to see how long the peel-off gel mask preparation dries on the skin surface. The significance value of $0.094>0.05$ is based on the results of statistical analysis using the one-way ANOVA test, which means that the concentrations of PVA and HPMC have no significant effect on the drying time of the peel-off gel mask preparation of ethanol extract of yarrow (A. millefolium) as anti-aging. The drying time for gel mask formulations 
varies between 15 and 30 min [36]. The results obtained in formula I are $31 \mathrm{~min}$, which does not meet the existing standards, however, the results obtained in formula II-V are still in the range of 15-30 min, which meets the drying time requirements for the gel mask preparation. The concentration of PVA has a significant impact on the speed with which the preparation dries; the higher the PVA concentration, the faster the preparation dries. PVA operates through the development process by attaching existing water molecules, causing attraction between water molecules and an increase in cohesiveness [21].

\section{Conclusion}

1. With varying percentages of PVA and HPMC, the ethanol extract of yarrow (A. millefolium) can be formed into a peel-off gel mask preparation as an anti-aging agent.

2. The amount of PVA and HPMC used as a filmforming and gelling agent had a substantial impact on the quality of the peel-off gel mask made from ethanol extract of yarrow; in this case, the combination of PVA and HPMC boosted dispersion but reduced viscosity.

\section{References}

1. Wahyuni DK, Ekasari W, Witono JR, Purnobasuki H. Indonesian Toga. Surabaya: Surabaya: Airlangga University Press; 2016.

2. Bimbiraitè $K$, Ragažinskienè $O$, Maruska $A$, Kornyšova $O$. Comparison of the chemical composition of four yarrow (Achillea millefolium L.) morphotypes. Biologija. 2008;54(3):208-12. https://doi.org/10.2478/v10054-008-0046-0

3. Pain S, Altobelli C, Boher A, Cittadini L, Favre-Mercuret M, Gaillard C, et al. Surface rejuvenating effect of achillea millefolium extract. Int J Cosmet Sci. 2011;33(6):535-42. https:// doi.org/10.1111/j.1468-2494.2011.00667.x

PMid:21711463

4. Fiume MZ. Final report on the safety assessment of yarrow (Achillea millefolium) extract. Int J Toxicol. 2001;20(2):79-84. https://doi.org/10.1080/10915810160233785

5. Melfa F, Siragusa D, Caruso D, Lo Faro C, Nicoletti GF, Rauso R. At-home cosmeceutical application and outpatient treatments: A 3D stepwise facial rejuvenation approach. Open Access Maced J Med Sci. 2020;8(B):1041-6.

6. Cadet J, Douki T, Pouget JP, Ravanat JL, Sauvaigo S. Effects of UV and visible radiations on cellular DNA. Curr Probl Dermatol. 2001;29:62-73. https://doi.org/10.1159/000060654

PMid:11225202

7. Shanbhag S, Nayak A, Narayan R, Nayak UY. Anti-aging and sunscreens: Paradigm shift in cosmetics. Adv Pharm Bull. 2019;9(3):348-59. https://doi.org/10.15171/apb.2019.042 PMid:31592127

8. Indrisari M, Sartini S, Miskad UA, Djawad K, Amir Tahir K, Nurkhairi N, Muslimin L. Photoprotective and inhibitory activity of tyrosinase in extract and fractions of Terminalia catappa L. Open Access Maced J Med Sci. 2021;9(A):263-70.

9. Ginting M, Fitri K, Leny L, Lubis BK. Clay mask formulation and anti aging effectiveness from ethanol extract of yellow potato (Solanum tuberosum L.). J Dunia Farm. 2020;4(2):68-75.

10. NazliniwatyN, Harun FR, Putra ED, Nerdy N. Antiaging activity of gel preparation containing three varieties of passion fruit pee ethanolic extract. Open Access Maced J Med Sci. 2020;8:170-4.

11. Gaweł-Beben K, Strzępek-Gomółka M, Czop M, Sakipova Z, Głowniak K, Kukula-Koch W. Achillea millefolium L. and Achillea biebersteinii Afan. Hydroglycolic extracts-bioactive ingredients for cosmetic use. Molecules. 2020;25(15):3368. https://doi. org/10.3390/molecules 25153368

12. Voight R. Pharmaceutical Technology Textbook. Yogyakarta: Gadjah Mada University Press; 1994.

13. Ahmed MM, Ali MM. Semisolid dosage form: Topical ge formulation a review. World J Pharm Res. 2016;5(12):1256-68.

14. NabiSA, SherazMA,AhmedS, Mustaan N,AhmadI. Pharmaceutical gels: A review. RADS J Pharm Pharm Sci. 2016;4(1):40-8.

15. Effionora A. Excipients in Pharmaceutical Preparations. Jakartra: Dian Rakyat; 2012.

16. Mohiuddin AK. An extensive review of cosmetics in use. OSP $J$ Clin Trials Rev. 2019;1(1):1-20.

17. Amaliah RN, Rahmawanty $\mathrm{D}$, Ratnapuri $\mathrm{PH}$. Variations in PVA and HPMC concentration on the physical stability of peel-off gel masks papaya seed extract (Carica papaya L.). J Pharmasci. 2018;5(1):78-85. https://doi.org/10.20527/jps.v5i1.5789

18. Siregar AB, Utara S, Bulan R, Yusak Y, Utara US. Antibacterial and antioxidant properties of leave and stem bark extract of artocarpus heterophyllus as the component of peel-off mask. Int J Sci Technol Eng. 2018;5(4):101-6.

19. Prasetyo BE, Rafika D, Laila L, Aminah F. Physical evaluation and anti-aging effect of red bean ethanolic extract (Vigna angularis (Wild.) Ohwi \& Ohashi) peel-off gel mask, Open Access Maced J Med Sci. 2019;7(22):3907-10.

20. Zebua N, Saputri M, Sijabat WG, Wulandari IA, Nofriani I, Zai WA, et al. Incision wound healing test of ethanolic extract gel from salaon (Parsonsia alboflavescens [Dennst.] Mabb.) Leaves in male rats. Open Access Maced J Med Sci. 2021;9(A):776-81.

21. Warnida H, Oktaviani R. Formulation of peel-off gel mask ethanol extract of dayak onion bulbs (Eleutherine bulbosa (Mill.) Urb.). Med Sains. 2016;9(2):167-73.

22. Kuncari ES, Iskandarsyah P. Evaluation, physical stability test and syneresis of gel containing minoxidil, apigenin and celery (Apium graveolens L.) Juice. 2014;42(4):213-22.

23. Masluhiya SA, Fidiastuti HR. Natural face mask's effectiveness in increasing facial skin moisture. Care J IIm IImu Kesehat. 2019;7(3):138. https://doi.org/10.33366/jc.v7i3.1389

24. Sugiyono P. Qualitative Quantitative Research Methods and R \& D. Bandung: ALFABETA; 2013.

25. Lakshmi T, Geetha RV, Roy A, Kumar SA. Yarrow (Achillea millefolium Linn.) a herbal medicinal plant with broad therapeutic use-a review. Int J Pharm Sci Rev Res. 2011;9(2):136-41.

26. Rowe RC, Sheskey PJ, Quinn ME. Handbook of Pharmaceutical Excipients. Building, Washington, DC: Pharmaceutical Press and American Pharmacists Association; 2009.

27. Rahmawati DR, Harianto ZA, Afianty NA, Amalia L, Ariani C. Formulation and Antioxidant Test of Chromolaena odorata Leaf Extract in Gel with DPPH Method (1, 1-Diphenyl-2-Picril Hydrazil). 2018. p. 978-9. Available from: https://www.dspace.uii. ac.id/handle/123456789/12337. [Last accessed on 2017 Sep 17].

28. Titaley S, Fatimawali, Lolo WA. Effectiveness and formulation gel preparations of api-api mangrove leaf ethanol extract (Avicennia marina). UNSRAT J IIm Farm. 2014;3(2):99-106.

29. Latifah F, Iswari R. Handbook of Cosmetic Science. Jakarta: Gramedia Pustaka Utama; 2013. 
30. Indriaty S, Rizikiyan Y, Firmansyah D, Tinggi S, Muhammadiyah F, Fulica A. Stability and formulation antiaging gel using ethanol extract from red dragon fruit skin (Hylocereus polyrhizus) and snail slime (Achatina fulica) with gelling variations. Journal of Pharmacopolium. 2019;2(2):104-11.

31. Sinko PJ. Martin Pharmacy Physics and Pharmaceutical Sciences. $5^{\text {th }}$ ed. Jakarta: Buku Kedokteran EGC; 2011.

32. Sukmawati NM, Arisanti Cl, Wijayanti NP. Variations in PVA, HPMC, and glycerin concentrations on the physical properties of a peel-off gel face mask with 96 percent ethanol extract mangosteen peel (Garcinia mangostana L.). J Farm Udayana. 2013;2(3):35-42.

33. Emelda E. Formulation and physical properties testing of a single gel with ethanolic extract of red betel leaf (Piper crocatum) and cinnamon oil (cinnamon oil). Indones Pharm Nat Med J. 2020;4(2):43. https://doi.org/10.21927/inpharnmed.v4i2.1405

34. Garg A, Aggarwal D, Garg S, Singla AK. Spreading of semisolid formulations: An update. Pharm Technol North Am. 2002;26(9):84-105.

35. Naibaho $\mathrm{OH}$, Yamlean PV, Wiyono W. Effect of ointment base on basil leaf extract (Ocimum sanctum L.) ointment formulation on the back skin of rabbits infected with Staphylococcus aureus. J IIm Farm. 2013;2(2):27-34.

36. Reiger MM. Harry 's Cosmeticology. The United States of America: Chemical Publishing; 2000. 